\title{
Pengaruh Kualitas Jasa Terhadap Tingkat Kepuasan Mahasiswa Akuntansi Dalam Mengikuti Pendidikan Profesi Akuntansi (Ppak)
}

\author{
Suwaldiman * \\ Afuan Fajrian Putra **
}

\begin{abstract}
This research examines whether there are any differences among the service quality against the satisfaction of PPAk students; and tests the impacts of service quality to the students' satisfaction. Service quality is represented by reliability, responsiveness, assurance, empathy, and tangible. This research is conducted to the students who are undertaking accounting profession education in UII, UGM, STIE YKPN and Universitas Sanata Darma.Purposive sampling is employed in which 100 samples were distributed and 87 of those are processed. Based on the paired samples $T$ Test and multiple linear regression analysis, this research reveals that there are no differences found among the service quality against the satisfaction of PPAk students. In addition, reliability, responsiveness, empathy, and tangible affect positively to the students' satisfaction. However, assurance does not affect positively to the students' satisfaction.
\end{abstract}

Keywords: Service quality, reliability, responsiveness, assurance, empathy, tangible, students' satisfaction.

* Dosen Fakultas Ekonomi UII

** Alumni Fakultas Ekonomi UII 


\section{Pendahuluan}

Kualitas pelayanan menjadi faktor yang menentukan dalam melihat keberhasilan suatu lembaga yang bergerak di bidang produksi maupun jasa pelayanan, baik yang dikelola oleh badan swasta maupun pemerintah.Pelayanan merupakan suatu bentuk kegiatan sosial untuk membantu orang lain dan mempunyai tujuan membangun kerja sama antar pihak dalam jangka panjang dengan prinsip saling menguntungkan antar pihak terkait. Pelayanan yang berkualitas adalah pelayanan yang dapat memahami keinginan dan kebutuhan konsumen serta berusaha untuk memberikan nilai lebih kepadapelanggan. Dari pengertian diatas dapat dipahami bahwa peran kualitas pelayanan yang baik merupakan hal sangat penting dan sangat berpengaruh, tanpa adanya pelayanan yang tepat produk akan kurang diminati oleh konsumen. Oleh karena itu pelayanan harus meliputi lima dimensi yang dikembangkan oleh Parasuraman, Zeithaml dan Berry (1988) yang terdiri dari reliabilitas (reiiability), daya tanggap (responsiveness), jaminan (assurance), empati (empathy) serta bukti fisik (tangibles). Mereka mengemukakan bahwa untuk menentukan tingkat kualitas jasa dapat didasarkan pada salah satu atau kombinasi dari 5 gap (perbedaan) penilaian, baik yang berasal dari penilaian kondisi konsumen maupun pemasar (perusahaan). Di antara 5 gap tersebut, gap ke-5 yang menunjukkan jasa yang diharapkan konsumen dengan persepsi jasa yang diperoleh konsumen, banyak digunakan sebagai dasar konseptual penelitian jasa.

Pendidikan Profesi Akuntansi (PPAk) merupakan salah satu bagian yang berada dalam naungan fakultas, dalam hal ini berada dalam lingkungan Fakultas Ekonomi Prodi Akuntansi. Pendidikan Profesi Akuntansi (PPAk) merupakan jenjang pendidikan tambahan yang ditujukan bagi seorang lulusan sarjana ekonomi jurusan akuntansi yang 
ingin mendapatkan gelar Akuntan. Surat Keputusan (SK) Mendiknas No. 179/U/2001 menyatakan bahwa lulusan sarjana strata satu (S1) jurusan akuntansi berkesempatan menempuh Pendidikan Profesi Akuntansi di perguruan tinggi yang telah ditunjuk oleh Direktorat Jenderal Pendidikan Tinggi. Mereka yang telah menempuh Pendidikan Profesi Akuntansi nantinya akan berhak memperoleh sebutan profesi Akuntan (Ak), dan juga semakin berpeluang meniti karir sebagai auditor pemerintahan, auditor internal, akuntan sektor publik, akuntan manajemen, akuntan pendidik, akuntan perpajakan, akuntan keuangan, maupun akuntan sistem informasi.

Untuk menunjang system perkuliahan di PPAk diperlukan sarana dan prasarana baik fisik maupun non fisik yang memadai agar mahasiswa yang mengikuti Pendidikan Profesi Akuntansi (PPAk) merasa nyaman dan mendapat hasil sesuai yang diharapkan sebelumnya. Tidak sedikit mahasiswa yang mengeluh tentang kualitas pelayanan yang diberikan. Mahasiswa merasakan bahwa pelayanan yang diberikan jauh dari harapan mereka. Permasalahan dosen dalam ketepatan mengajar mahasiswanya, respon yang sangat lamban dari unsur-unsur fakultas menjadikan permasalahan mahasiswa Fakultas Ekonomi menjadi lebih komplek, kelengkapan peralatan perkuliahan yang tidak begitu memadai, dan lain sebagainya. Sedangkan salah satu kunci kesuksesan sebuah lembaga atau instansi terletak pada kualitas pelayanan yang memuaskan yang diberikan kepada konsumennya. Dari kualitas pelayanan yang baik akan menjadikan mahasiswa menjadi puas terhadap pelayanan yang telah diberikan oleh pihak fakultas.

Berdasarkan uraian latar belakang diatas, maka rumusan masalah dalam penelitian ini adalah:apakah ada perbedaan antara kualitas jasa dengan kepuasan mahasiswa PPAk; dan apakah ada penganuh dimensi 
kualitas (reliability, responsiveness, assurance, empathy,dan tangibles) terhadap kepuasan mahasiswa PPAk. Penelitian ini bertujuan untuk menguji apakah ada perbedaan antara kualitas jasa yang diselengarakan oleh penyelenggara PPAk dengan tingkat kepuasan yang diperoleh para peserta didik. Penelitian ini juga menguji apakah variabel dimensi kualitas berpengaruh terhadap tingkat kepuasan peserta didik PPAk.

Hasil penelitian ini diharapkan bermanfaat bagi penyelenggara PPAk dalam mengevaluasi kualitas jasa yang disediakan terhadap para peserta didik, sehingga perbaikan kualitas jasa bisa selalu dilakukan sesuai dengan tuntutan para peserta didik sebagai konsumen PPAk.

\section{Tinjauan Pustaka dan Pengembangan Hipotesis}

\section{Kualitas Jasa (Service Quality)}

Definisi kualitas jasa berpusat pada upaya pemenuhan kebutuhan dan keinginan pelanggan serta ketepatan penyampaiannya untuk mengimbangi harapan pelanggan. Kualitas jasa adalah tingkat keunggulan yang diharapkan dan pengendalian atas tingkat keunggulan tersebut untuk memenuhi keinginan pelanggan.

Parasuraman, Zeithaml dan Berry (1988) berpendapat ada lima dimensi kualitas jasa, yaitu :

a. Reliabilitas (reliability)

Berkaitan dengan kemampuan perusahaan untuk memberikan layanan yang akurat sejak pertama kali tanpa membuat kesalahan apapun dan menyampaikan jasanya sesuai dengan waktu yang disepakati.

b. Daya tanggap (responssiveness)

Berkenaan dengan kesediaan dan kemampuan para karyawan membantu para pelanggan dan merespons permintaan mereka, 
serta menginformasikan kapan jasa akan diberikan dan kemudian memberikan jasa secara cepat.

c. Jaminan (assurance)

Yakni perilaku karyawan mampu menumbuhkan kepercayaan pelanggan terhadap perusahaan dan perusahaan bisa menciptakan rasa aman bagi para pelanggannya. Jaminan juga berarti bahwa para karyawan selalu bersikap sopan dan menguasai pengetahuan dan ketrampilan yang dibutuhkan untuk menangani setiap pertanyaan atau masalah pelanggan.

d. Empati (empathy)

Berarti perusahaan memahami masalah pelanggannya dan bertindak demi kepentingan pelanggan, serta memberikan perhatian personal kepada para pelanggan dan memiliki jam operasi yang nyaman.

e. Bukti fisik (tangibles)

Berkenaan dengan daya tarik fasilitas fisik, perlengkapan dan material yang digunakan oleh perusahaan serta penampilan karyawan.

\section{Kepuasan Konsumen}

Kotler and Killer (2006) mendefinisikan kepuasan sebagai perasaan senang atau kecewa seseorang yang dihasilkan dari perbandingan persepsi pada kinerja produk dengan harapannya. Pengertian seperti itu menimbulkan pendapat bahwa metode pengukuran jasa dan kepuasan pelanggan pada dasarnya sama, yaitu membandingkan harapan dengan kinerja. Lebih jauh Zeithaml, Bitner and Gremler (2006) menyatakan bahwa kualitas jasa dan kepuasan pelanggan secara fundamental berbeda dalam hal sebab dan akibat. Kepuasan sebagai konsep yang lebih luas, 
sedangkan kualitas jasa secara khusus berfokus pada dimensi jasa, sehingga persepsi kualitas jasa adalah bagian dari kepuasan.

Di samping itu, Yuksel and Rimington (1998) mendefinisikan kepuasan sebagai evaluasi keputusan setelah pelanggan mengkonsumsi produk/jasa melalui keyakinan mereka tentang pentingnya setiap atribut. Mereka juga membedakan penilaian kepuasan berdasarkan faktor: (1) kinerja saja, (2) kinerja ditimbang dengan kepentingan, (3) kepentingan dikurangi kinerja, (4) penegasan langsung tentang kepuasan pelanggan, (5) penegasan langsung ditimbang dengan kepentingan, atau (6) kinerja dikurangi prediksi harapan. Penilaian dengan cara pertama (kinerja saja) memberikan hasil yang lebih memuaskan dari pada cara yang lain, sedangkan cara kedua, keempat dan kelima tidak akan membuat substansial validitas prediksinya meningkat.

Sedangkan menurut Assegaff (2009) kepuasan konsumen adalah suatu ukuran yang merefleksikan antara struktur, proses dan hasil akhir pelayanan. Kepuasan konsumen di pandang sebagai konsep multi dimensional yang melibatkan biaya, kemudahan sarana, aspek teknis dan interpersonal serta hasil akhir. Kepuasan juga dapat di pertimbangkan sebagai hubungan antara harapan dan pengalaman, dimana semakin dekat dengan harapan akan semakin puas konsumen.

Mencermati keterangan di atas, maka dalam penelitian ini kepuasan akan diukur dengan menggunakan atribut atau indikator dari lima dimensi kualitas jasa (keandalan, kepastian/jaminan, responsif, empati dan berujud).

\section{Pengembangan Hipotesis}

\section{Perbedaan Antara Kualitas Jasa Dengan Kepuasan Mahasiswa PPAk}

Parasuraman, Zeithaml, dan Berry (1988) menelititentang kualitas pelayanan sebagai suatu bentuk sikap yang berkaitan dengan kepuasan, 
sebagai hasil dari perbandingan antara harapan dengan kinerja. Mereka menetapkan lima model gap pengukuran kualitas jasa, yaitu berdasarkan perbedaan: (1) jasa yang diharapkan konsumen dengan persepsi manajemen tentang harapan konsumen, (2) persepsi manajemen tentang harapan konsumen dengan perwujudan persepsi menjadi spesifikasi kualitas jasa, (3) perwujudan persepsi menjadi spesifikasi kualitas jasa dengan penyampaian jasa, (4) penyampaian jasa dengan komunikasi eksternal ke pelanggan, dan (5) jasa yang diharapkan konsumen dengan persepsi jasa yang diperoleh konsumen.

Seiring dengan kualitas pelayanan jasa yang diberikan, maka konsumen akan bisa memberi penilaian terhadap jasa yang telah diterimanya. Konsumen akan merasa puas apabila jasa yang disediakan sesuai dengan apa yang dibutuhkan oleh konsumen. Begitu pula sebaliknya, apabila jasa yang diterima tidak sesuai dengan apa yang dibutuhkan oleh konsumen maka konsumen tersebut tidak puas terhadap kualitas jasa yang diberikan. Atas dasar penjelasan diatas maka dapat dibuat hipotesis sebagai berikut:

$\mathrm{H1}$ : Tidak ada perbedaan antara kualitas jasa dengan tingkat kepuasan.

\section{Pengaruh Reliability Terhadap Kepuasan Mahasiswa}

Menurut Parasuraman, Zeithmal, dan Berry (1988) berpendapat bahwa reliability atau keandalan adalah kemampuan untuk melaksanakan pelayanan yang semestinya secara tepat. Dimensi ini sangat penting bagi sebagian pelanggan, sehingga mereka bersedia mengeluarkan biaya tambahan agar perusahaan melaksanakan transaksi seperti yang di janjikan.

Menurut Gorpersz (dikutip oleh Assegaff, 2009) menyatakan bahwa kendalan berkaitan dengan probabilitas atau kemungkinan suatu produk melaksanakan fungsinya secara berhasil dalam periode waktu 
tertentu di bawah kondisi tertentu dengan demikian keandalan merupakan karakteristik yang merefleksikan kemungkinan atau probabilitas tingkat keberhasilan dalam penggunaan produk itu.

Pengaruh reliability terhadap kepuasan mahasiswa adalah keandalan mempunyai pengaruh positif terhadap kepuasan mahasiswa. Semakin tinggi tingkat keandalan semakin tinggi pula kualitas layanan yang di terima oleh mahasiswa. Namun sebaliknya semakin rendah tingkat keandalan yang di terima mahasiswa, maka kepuasan mahasiswa pun rendah. Atas dasar penjelasan di atas maka dapat di buat hipotesis sebagai berikut :

H2 : Reliability berpengaruh positif terhadap kepuasan Mahasiswa.

\section{Pengaruh Responsiveness Terhadap Kepuasan Mahasiswa}

Menurut Parasuraman, Zeithaml, dan Berry (1988) responsiveness atau ketanggapan adalah keinginan untuk membantu konsumen dan memberikan pelayanan yang cepat. Dimensi ini menekankan pada perhatian dan kecepatan dalam menghadapi permintaan, pertanyaan, keluhan serta kesulitan pelanggan.

Menurut Assegaff (2009) suatu kebijakan untuk membantu dan memberikan pelayanan yang cepat kepada pelanggan, membiarkan konsumen menunggu, tanpa adanyà suatu alasan yang jelas akan menyebabkan persepsi yang negatif dalam kualitas pelayanan. Pada peristiwa pelayanan yang gagal, kemampuan untuk segera mengatasi hal tersebut secara profesional dapat memberikan persepsi yang positif terhadap kualitas pelayanan.

Pengaruh responsiveness atau ketanggapan adalah semakin tinggi tingkat ketanggapan, semakin tinggi pula kualias layanan yang di terima oleh mahasiswa. Namun sebaliknya, semakin rendah tingkat keandalan 
yang di berikan maka tingkat kepuasan mahasiswa juga semakin rendah. Atas dasar penjelasan di atas, maka dapat di buat hipotesis yaitu :

H3 : Responsiveness berpengaruh positif terhadap kepuasan Mahasiswa .

\section{Pengaruh Assurance Terhadap Kepuasan Mahasiswa}

Menurut Parasuraman, Zeithaml, dan Berry (1988) menyatakan bahwa assurance atau jaminan adalah pengetahuan, keramahan, serta kemampuan karyawan untuk menimbulkan kepercayaan pelanggan terhadap perusahaan.

Sedangkan menurut Tjiptono (dikutip oleh Naryawan, 2011) menyatakan bahwa jaminan adalah mencakup pengetahuan, kemampuan, kesopanan dan sifat dapat di percaya yang di miliki oleh para staf, bebas dari bahaya, risiko atau kerugian. Pengetahuan dan keramahan karyawan serta kemampuan melakukan tugas secara spontan yang dapat menjamin kinerja yang baik sehingga menimbulkan kepercayaan dan keyakinan pelanggan.

Pengaruh assurance atau jaminan pada kepuasan mahasiswa adalah semakin tinggi jaminan semakin tinggi pula kualitas layanan yang di terima mahasiswa. Namun sebaliknya, jika jaminan yang di berikan kepada mahasiswa rendah, maka akan timbul ketidakpuasan mahasiswa atas dasar penjelasan tesebut, maka dapat di buat hipotesis sebagai berikut:

H4 : Assurance atau jaminan berpengaruh positif terhadap kepuasan Mahasiswa.

\section{Pengaruh Empathy Terhadap Kepuasan Mahasiswa}

Menurut Parasuraman, Zeithaml, dan Berry (1988) emphaty atau empati adalah perhatian secara individu yang di berikan oleh penyedia jasa sehingga pelanggan merasa penting, dihargai, dan dimengerti oleh perusahan. 
Menurut Assegaff (2009) empati juga berarti memberikan perhatian yang bersifat individual atau pribadi kepada pelanggan dan berupaya untuk memahami keinginan konsumen. Tingkat kepedulian dan perhatian perusahaan pada pelangganya secara individu akan sangat di dambakan oleh pelanggan. Persoalan dan masalah dapat muncul dan sejauh mana tingkat kepedulian untuk menyelesaikan masalah, mengerti kemauan dan kebutuhan pelanggan dapat di aktualisasikan.

Pengaruh emphaty atau empati pada kepuasan mahasiswa adalah semakin tinggi empati, maka semakin tinggi pula kualitas layanan yang di terima mahasiswa. Namun sebaliknya, semakin rendah empati yang berikan kepada pelanggan, maka kepuasan mahasiswa pun akan rendah. Atas dasar penjelasan tersebut, maka dapat di buat hipotesis sebagai berikut :

H5 :Emphaty berpengaruh positif terhadap kepuasan Mahasiswa.

\section{Pengaruh Tangible Terhadap Kepuasan Mahasiswa}

Menurut Parasuraman, Zeithaml, dan Berry (1988) tangible atau keberwujudan adalah penampilan fasilitas fisik, peralatan, personil dan perlengkapan komunikasi. Dimensi tangible ini umumnya di gunakan perusahaan untuk menaikan image di mata konsumen.

- Menurut Assegaff (2009) penampilan dan kemampuan sarana dan prasarana fisik harus dapat di andalkan, keadaan lingkungan di sekitarnya adalah bukti nyata dari pelayanan yang di berikan oleh pemberi jasa. Penampilan fisik pelayanan, karyawan, dan komunikasi akan memberikan warna tersendiri dalam pelayanan pelanggan.

Pengaruh tangible atau bukti fisik terhadap kepuasan mahasiswa adalah semakin tinggi bukti fisik yang di terima maka semakin tinggi pula kualitas layanan yang di terima oleh mahasiswa. Namun, bila persepsi mahasiswa terhadap bukti fisik rendah, maka kepuasan mahasiswa pun 
rendah. Atas penjelasan tersebut, maka dapat di buat hipotesis sebagai berikut :

H6 :Tangible/ bukti fisik berpengaruh positif terhadap kepuasan mahasiswa.

\section{Metode Penelitian}

\section{Populasi dan Sampel}

Populasi dalam penelitian ini adalah mahasiswa yang sedang mengambil PPAk di perguruan tinggi di Yogyakarta yang terdiri dari Univeristas Islam Indonesia, Universitas Gadjah Mada, Sekolah Tinggi Ilmu Ekonomi YKPN, Universitas Teknologi Yogyakarta, dan Universitas Sanata Darma.Sampel dipilih secara acak berdasarkan kemudahan untuk ditemui dan kesediaan untuk mengisi kuesioner. Teknik pengambilan sampel dalam penelitian ini yaitu purposive random sampling. Sampel yang digunakan dalam penelitian ini berjumlah 120 orang yang mewakili dari masing-masing penyelenggara PPAk di Yogyakarta.

\section{Sumber Data dan Teknik Pengumpulan Data}

Sumber data yang digunakan dalam penelitian ini adalah data primer. Data primer adalah data yang langsung dari sumber data penelitian yang diperoleh secara langsung dari sumber aslinya dan tidak melalui media perantara (Azwar, 1998). Sedangkan teknik pengumpulan data pada penelitian ini adalah dengan menggunakan kuesioner. Kuesioner adalah daftar pertanyaan yang harus dijawab dan atau daftar isian yang harus diisi oleh responden (Azwar, 1998).

Skala pengukuran yang digunakan dalam penelitian ini adalah skala Likert. Menurut Umar (2001), skala Likert berhubungan dengan 
pertanyaan tentang sikap seseorang terhadap sesuatu. Skala pengukuran pada penelitian ini adalah dengan menggunakan skala likert 1-4.

\section{Definisi dan Operasionalisasi Variabel}

Variabel independen dalam penelitian ini adalah reliability (kendalan), responsiveness (ketanggapan), assurance (jaminan), emphaty (empati), dan tangible (bukti fisik). Variabel dependen dalam penelitian ini menggunakan tingkat kepuasan mahasiswa dalam mengikuti pendidikan profesi akuntansi. Setiap variable diukur dengan menggunakan skala likert $1-4$.

\section{Metode Analisis Data}

Uji Dua Sampel Berhubungan (Paired Samples T Test)

Uji dua sampel berhubungan (Paired Samples T Test) digunakan untuk menguji ada-tidaknya perbedaan antara kualitas jasa yang diselengarakan oleh penyelenggara PPAk dengan tingkat kepuasan yang diperoleh para peserta didik.

\section{Analisis Regresi Berganda}

Analisis regresi digunakan untuk memprediksi pengaruh lebih dari satuvariabel bebas terhadap satu variabel tergantung, baik secara parsial maupunsimultan. Mengingat penelitian ini menggunakan lima variabel bebas, makapersamaan regresinya sebagai berikut :

$$
Y=a+\beta_{1} X_{1}+\beta_{2} X_{2}+\beta_{3} X_{3}+\beta_{4} X_{4}+\beta_{5} X_{5}+e
$$

\section{Keterangan:}

$\mathrm{Y}=$ Tingkat kepuasan mahasiswa akuntansi dalam mengikuti PPAk $\mathrm{a}=$ Konstanta, $\mathrm{X}_{1}=$ Reliability, $X_{2}=$ Responsiveness, $X_{3}=$ Assurance, $\mathrm{X}_{4}=$ Empathy, $\mathrm{X}_{5}=$ Tangible, $\mathrm{e}=$ Error, $\square 1 \ldots \quad \square n=$ Koefisien arah regresi 


\section{Hasil dan Pembahasan}

\section{Uji Beda Sampel Berhubungan (Paired Samples T Test)}

Uji Beda Sampel Berhubungan (Paired Samples T Test)dalam penelitian ini memasukkan indikator masing-masing variabel yaitu dari variabel kualitas jasa $(x)$ dan dari variabel kepuasan (y), serta dari ratarata masing-masing variabel.

Tabel 1: Hasil Uji Beda Sampel Berhubungan (Paired Samples T Test)

\begin{tabular}{lr}
\hline \multicolumn{1}{c}{ Indikator } & Sig (2-tailed) \\
\hline Rata-Rata Reliability (X) - Rata-Rata Reliability (Y) & 0,104 \\
Rata-Rata Assurance (X) - Rata-Rata Assurance (Y) & 0,487 \\
Rata-Rata Empathy (X) - Rata-Rata Empathy (Y) & 0,281 \\
Rata-Rata Tangible (X) - Rata-Rata Tangible (Y) & 1,000 \\
\hline \multicolumn{2}{c}{ Sumber: Data primer diolah }
\end{tabular}

Berdasarkan tabel 1 di atas dapat dilihat bahwa nilai Sig (2-tailed) > 0,05 yang berarti bahwa Ho diterima. Dengan nilai signifikan yang paling dominan adalah Rata-rata Tangible (X) - Rata-rata Tangible (Y) sebesar 1,000. Sedangkan rata-rata responsiveness $(x)$ dengan rata-rata responsiveness $(y)$ tidak bisa dibandingkan karena mean, standar deviasi, dan standar error mean mempunyai nilai yang sama sehingga perbedaannya 0 .Dari analisis diatas dapat ditarik kesimpulan bahwa hipotesis yang pertama yaitu tidak ada ada perbedaan antara kualitas jasa dengan tingkat kepuasan dapat diterima.

\section{Analisis Regresi Linier Berganda}

Untuk mempermudah perhitungan regresi dari data yang cukup banyak maka dalam penelitian ini diselesaikan dengan bantuan komputer program SPSS 17. 
Tabel 2: Hasil Uji Regresi Linear Berganda

\begin{tabular}{lccc}
\cline { 1 - 1 } Variabel Bebas & Koef. Beta & t-hitung & Probabilitas \\
\cline { 1 - 1 } Constanta & 0.683 & 0.952 & 0.344 \\
Reliability (X1) & 0.947 & 4.051 & 0.000 \\
Responsiveness (X2) & 1.550 & 8.667 & 0.000 \\
Assurance (X3) & 0.283 & 1.588 & 0.116 \\
Empathy (X4) & 0.724 & 3.856 & 0.000 \\
Tangible (X5) & 1.287 & 5.804 & 0.000 \\
R & & 0.941 & \\
R Square & & 0.886 & \\
Adjusted R Square & & 0.878 & \\
F Hitung & & 125.360 & \\
\hline
\end{tabular}

Sumber: Data Primer Diolah

Berdasarkan hasil analisis regresi linear pada tabel 2 maka dihasilkan persamaan regresi linier berganda sebagai berikut:

$\mathrm{Y}=0,683+0,947 \mathrm{X} 1+1,550 \mathrm{X} 2+0,283 \mathrm{X} 3+0,724 \mathrm{X} 4+1,287 \mathrm{X} 5+\mathrm{e}$

Hasil analisis regresi menunjukkan bahwa kepuasan mahasiswa dipengaruhi oleh variabel X1(reliability), $\mathrm{X} 2$ (responsiveness), $\mathrm{X} 4$ (empathy), dan X5 (tangible). Sedangkan variabel yang tidak berpengaruh terhadap variabel kepuasan mahasiswa adalah variabel X3 (assurance). R Square untuk model ini adalah $87.8 \%$. Ternyata hasil regresi mendukung hipotesis $2,3,4$, dan 6 ; yakni variabel reliability, responsiveness, empathy dan tangible berpengaruh positiv terhadap variäbel kepuasan mahasiswa.

Bukti empiris tidak mendukung hipotesis 3, karena ternyata hasilnya menunjukkan bahwa koefisien regresi tidak signifikan, yang berarti kepuasan tidak dipengaruhi oleh variabel assurance. Hasil penelitian ini sesuai dengan penelitian Achmad Zaeni (2007) yang menyimpulkan bahwa assurance tidak berpengaruh positif terhadap tingkat kepuasan mahasiswa akuntansi dalam mengikuti PPAk. Hal ini disebabkan karena tingkat kepuasan tidak dipengaruhi oleh kemampuan 
pengetahuan dosen yang luas dikarena mahasiswa PPAk dituntut kreatif dalam belajar dan sekaligus dituntun untuk mampu memecahkan masalah-masalah perkuliahan. Selain itu keberadaan dosen bukan menjadi faktor penentu kepuasan dikarenakan kemajuan teknologi yang bisa membawa mahasiswa berinteraksi dengan dosen tanpa harus bertatap muka. Tingkat kepuasan juga tidak dipengaruhi oleh ketrampilan karyawan karena mahasiswa tidak menganggap karyawan sebagai bagian dari pelayanan yang diberikan oleh pihak PPAk. Pelayanan yang diberikan oleh karyawan tidak bisa diukur secara kongkrit karena mahasiswa tidak mengetahui apakah pelayanan yang diberikan oleh karyawan sudah maksimal.

\section{Kesimpulan, Keterbatasan dan Saran}

\section{Kesimpulan}

Berdasarkan - pengujian hipotesis maka dapat ditarik kesimpulan sebagai berikut :

a. Tidak ada perbedaan antara kualitas jasa dengan tingkat kepuasan mahasiswa akuntansi dalam mengikuti Pendidikan Profesi Akutansi (PPAk) dimana rata-rata tangible (x) dengan rata-rata tangible (y) mempunyai nilai yang lebih dari pada rata-rata perbandingan reliability, assurance, empathy. Untuk variabel responsiveness tidak bisa dibandingkan karena mempunyai mean, standard deviation, dan standard error mean yang sama.

b. Reliability mempunyai pengaruh positif terhadap tingkat kepuasan mahasiswa akuntansi dalam mengikuti Pendidikan Profesi Akuntansi (PPAk), hal ini dibuktikan dengan hasil $p$ value variabel reliability yang lebih kecil dari tingkat signifikansi 0,05 . 
c. Responsiveness mempunyai pengaruh positif terhadap tingkat kepuasan mahasiswa akuntansi dalam mengikuti Pendidikan Profesi Akuntansi (PPAk), hal ini dibuktikan dengan hasil $\mathrm{p}$ value variabel responsiveness yang lebih kecil dari tingkat signifikansi 0,05 .

d. Assurance tidak mempunyai pengaruh positif terhadap tingkat kepuasan mahasiswa akuntansi dalam mengikuti Pendidikan Profesi Akuntansi (PPAk), hal ini dibuktikan dengan hasil $p$ value variabel responsiveness yang lebih besar dari tingkat signifikansi 0,05 .

e. Empathy mempunyai pengaruh positif terhadap tingkat kepuasan mahasiswa akuntansi dalam mengikuti Pendidikan Profesi Akuntansi (PPAk), hal ini dibuktikan dengan hasil $\mathrm{p}$ value variabel empathy yang lebih kecil dari tingkat signifikansi 0,05 .

f. Tangible mempunyai pengaruh positif terhadap tingkat kepuasan mahasiswa akuntansi dalam mengikuti Pendidikan Profesi Akuntansi (PPAk), hal ini dibuktikan dengan hasil $\mathrm{p}$ value variabel tangible yang lebih kecil dari tingkat signifikansi 0,05 .

\section{Keterbatasan}

Penelitian ini memiliki keterbatasan sebagai berikut :

a. Penelitian ini hanya menggunakan sampel dan bukan menggunakan populasi, sehingga data yang diperoleh kurang beragam.

b. Sampel pada penelitian ini hanya meliputi 4 universitas yang mempunyai prodi PPAk yaitu UI,UGM,STIE YKPN, dan USD.

c. Variabel dependent dalam penelitian ini hanya menggunakan tingkat kepuasan. 


\section{Saran}

Dalam penelitian ini peneliti memiliki keterbatasan-keterbatasan yang dapat dijadikan pedoman bagi peneliti selanjutnya, untuk sebaiknya memperhatikan hal-hal sebagai berikut :

a. Penelitian selanjutnya dapat menggunakan populasi untuk memperoleh responden penelitian yang lebih banyak sehingga data yang didapat akan lebih beragam.

b. Penelitian selanjutnya dapat menggunakan tambahan variabel dependent berupa loyalitas, yang menggambarkan loyalitas mahasiswa setelah memperoleh pelayanan yang baik terhadap instansi penyelenggara PPAk.

\section{DAFTAR PUSTAKA}

Balasubramanian, S., P. Konana and NM. Menon, (2003), Customer Satisfaction in Virtual Environments: A Study of Online Investing, Management Science, 49 (7): 871-889.

Barsky, JD. and R. Labagh, (1992), Measurement, Market Research, Hotels and Motels, Factors, Customer Satisfaction, Consumer Attitudes, Cornell Hotel and Restaurant Administration Quarterly, 33 (5), 37-44.

Bei, LT. and YC. Chiao, (2001), An Integrated Model for the Effects of Perceived Product, Perceived Service Quality, and Perceived Price Fairness on Costumer Satisfaction and Loyalty,Journal of Costumer Satisfaction, Dissatisfaction and Complaining Behavior, 14: 125-140.

FE UII, (2008), Pedoman Penulisan Skripsi Fakultas Ekonomi UII, Yogyakarta.

Fullerton, G, (2005), The Impact of Brand Commitment on Loyalty to Retail Service Brands, Canadian Journal of Administrative Science, 22 (2): 97-110.

Garbarino, E. and MS. Johnson, (1999), The Different Roles of Satisfaction, Trust and Commitment in Consumer Relationship, Journal of Marketing, 63(2): 70-87. 
Gujarati, N. Damodar, (2003), Basic Econometrics, $4^{\text {th }}$ Edition, New York: Mc Gaw-Hill Inc.

Hallowell, R., (1996), The Relationships of Customer Satisfaction, Customer Loyalty and Profitability: An Empirical Study, International Journal of Service Industry Management, 7 (4): 27-42.

Hogarth, jm., M. English and M. Sharma, (2001), Costumer Complaints and Third Paties: Determinants of Consumer Satisfaction with Complain, Journal of Consumer Satisfaction, Dissatisfaction and Complaining Behavior, 14: 74-78.

Huang, JH. and CY. Lin, (2005), The Explanation Effects on Costumer Perceived Justice, Satisfaction and Loyalty Improvement: An Exploratory Study, The Journal of American Academy of Business, Cambridge, 7(2): 212-218.

Ikatan Akuntan Indonesia, (2001), Standar Profesional Akuntan Publik, Januari, Jakarta: Salemba Empat.

Jun, S., YJ. Hyun., JM. Gentry and CS. Song, (2001), The Relative Influence of Affective Experience on Consumer Satisfaction Under Positive Versus, Journal of Consumer Satisfaction, Dissatisfaction and Complaining Behavior, 14: 141-154.

Kolodinsky, J., J. Nam, J. Lee and M. Drzewiczewsky, (2001), Degree of Frailty and Elders' Satisfaction with Personal Care Services in a Community Setting, Journal of Consumer Satisfaction, Dissatisfaction and Complaining Behavior, 14 (2): 154-165.

Kotler, P. and KL. Keller, (2006), Marketing Management, $12^{\text {th }}$ ed., New Jersey: Pearson Prentice Hall.

Lawton, JL., D. Weaver and B. Faulkner, (1998), Customer Satisfaction in Australian Timeshare Industry, Journal of Travel Research,

37(1): 30-38.

Lee,-J., J. Lee and L. Feick, (2001), The Impact of Switching Costs on the Consumer Satisfaction-Loyalty Link: Mobile Phone Service in France, Journal of Service Marketing, 15(1): 35-48.

Leo, PY. and J. Philippe, (2002), Retail Centers: Location and Customer's Satisfaction, The Service Industries Journal, 22(1): 122-146.

Meuter, LM., AL. Ostrom, RI. Roundtree and MJ. Bitner, (2000), SelfService Technologies: Understanding Customer Satisfaction with Technology-Based Service, Journal o Marketing, 64 (3): $50-64$.

Naryawan, (2011), Analisis Pengaruh Kualitas Pelayanan Terhadap Kepuasan Mahasiswa Pengguna Jasa Perpustakaan Referensi 
FE UNDIP, Skripsi S-1, Semarang: Fakultas Ekonomi Universitas Diponegoro.

Parasuraman, A., VA. Zeithmal and L. Berry, (1985), A Conceptual Model of Service Quality and Its Implication for Futura Research, Journal of Marketing, 49 (Fall): 41-50.

Prasetyaningrum, I.D, (2009), Analisis Pengaruh Pembelajaran dan

Kualitas Pelayanan Terhadap Kepuasan Mahasiswa dan

Loyalitas Mahasiswa, Tesis, Semarang: Program Pascasarjana Universitas Diponegoro.

Sekaran, Uma., (2000), Research Methods for Business A Skill Building Approach, $2^{\text {nd }}$ Edition, New York: John Willey \& Sons, Inc.

Srijumpa, R., M. Speece and H. Paul, (2002), Satisfaction Drivers for Internet Service Technology among Stock Brokerage, Journal of Financial Service Marketing, 6 (3): 240-253.

Tian-Cole, S., JL Crompton and VL Willson, (2002), An Empirical Investigation of the Relationships Between Service Quality, Satisfaction and Behavioral Intentions among Visitors to a Wildlife Refuge, Journal of Leisure Research, 34(1): 1-24.

$\mathrm{Yu}, \mathrm{CH}$., HC. Chang and GL. Huang, (2006), A Study of Service Quality,

Costumer Satisfaction and Loyalty in Taiwanese Leisure Industry, The Journal of American Academy of Business, Cambridge, 9(1): 126-133.

Yuksel, A. and M. Rimmington, (1998), Customer-Satisfaction Measurement, Cornell Hotel and Restaurant Administration Quartely, 39 (6): 60-68. =

Zaeni, A., (2007), Pengaruh Kualitas Pelayanan (Service Quality)

Terhadap Kepuasan Mahasiswa Fakultas Ekonomi Universitas Islam Negeri (UIN) Malang, Skripsi S-1, Malang: Fakultas Ekonomi Universitas Islam Negeri (UIN) Malang.

Zeithaml, VA., MJ. Bitner and DD. Gremler, (2006), Service Marketing:

Integrating Customer Focus Across the Firm, $4^{\text {th }}$ ed.,

Singapore: McGraw-Hill Companies, Inc 


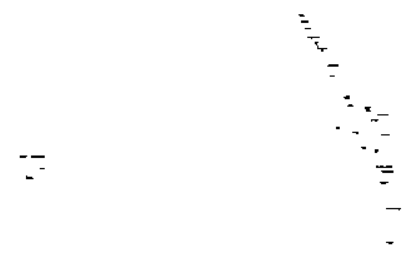

-...

$\therefore$ 